\title{
Genome-wide association studies for heat stress response in Bos taurus $\times$ Bos indicus crossbred cattle
}

\author{
Pamela I. Otto, ${ }^{1}$ Simone E. F. Guimarães, ${ }^{1}$ Lucas L. Verardo, ${ }^{1}$ Ana Luísa S. Azevedo, ${ }^{2}$ Jeremie Vandenplas, ${ }^{3}$ \\ Claudia A. Sevillano, ${ }^{3,4}$ Daniele B. D. Marques, ${ }^{1}$ Maria de Fatima A. Pires, ${ }^{2}$ Célio de Freitas, ${ }^{2}$ Rui S. Verneque, ${ }^{2}$ \\ Marta Fonseca Martins, ${ }^{2}$ João Cláudio C. Panetto, ${ }^{2}$ Wanessa A. Carvalho, ${ }^{2}$ Diego O. R. Gobo, ${ }^{1}$ \\ Marcos Vinícius G. B. da Silva, ${ }^{2}$ and Marco A. Machado ${ }^{2 *}$ \\ ${ }^{1}$ Department of Animal Science, Universidade Federal de Viçosa, Viçosa 36570-900, Brazil \\ ${ }^{2}$ Embrapa Dairy Cattle Research Center, Juiz de Fora 36038-330, Brazil \\ ${ }^{3}$ Wageningen University and Research Animal Breeding and Genomics, Wageningen 6700, the Netherlands \\ ${ }^{4}$ Topigs Norsvin Research Center, Beuningen 6640, the Netherlands
}

\section{ABSTRACT}

Heat stress is an important issue in the global dairy industry. In tropical areas, an alternative to overcome heat stress is the use of crossbred animals or synthetic breeds, such as the Girolando. In this study, we performed a genome-wide association study (GWAS) and post-GWAS analyses for heat stress in an experimental Gir $\times$ Holstein $\mathrm{F}_{2}$ population. Rectal temperature (RT) was measured in heat-stressed $\mathrm{F}_{2}$ animals, and the variation between 2 consecutive RT measurements $(\Delta \mathrm{RT})$ was used as the dependent variable. Illumina BovineSNP50v1 BeadChip (Illumina Inc., San Diego, CA) and single-SNP approach were used for GWAS. Post-GWAS analyses were performed by gene ontology terms enrichment and gene-transcription factor (TF) networks, generated from enriched TF. The breed origin of marker alleles in the $\mathrm{F}_{2}$ population was assigned using the breed of origin of alleles (BOA) approach. Heritability and repeatability estimates $( \pm$ standard error) for $\Delta \mathrm{RT}$ were $0.13 \pm 0.08$ and $0.29 \pm 0.06$, respectively. Association analysis revealed 6 SNP significantly associated with $\Delta \mathrm{RT}$. Genes involved with biological processes in response to heat stress effects (LIF, OSM, TXNRDQ, and DGCR8) were identified as putative candidate genes. After performing the BOA approach, the $10 \%$ of $\mathrm{F}_{2}$ animals with the lowest breeding values for $\Delta \mathrm{RT}$ were classified as low- $\Delta \mathrm{RT}$, and the $10 \%$ with the highest breeding values for $\Delta \mathrm{RT}$ were classified as high- $\Delta \mathrm{RT}$. On average, $49.4 \%$ of low- $\Delta \mathrm{RT}$ animals had 2 alleles from the Holstein breed (HH), and $39 \%$ had both alleles from the Gir breed (GG). In high- $\Delta \mathrm{RT}$ animals, the average proportion of animals

Received June 29, 2018

Accepted May 5, 2019.

*Corresponding author: marco.machado@embrapa.br for $\mathrm{HH}$ and GG were 1.4 and $50.2 \%$, respectively. This study allowed the identification of candidate genes for $\Delta$ RT in Gir $\times$ Holstein crossbred animals. According to the BOA approach, Holstein breed alleles could be associated with better response to heat stress effects, which could be explained by the fact that Holstein animals are more affected by heat stress than Gir animals and thus require a genetic architecture to defend the body from the deleterious effects of heat stress. Future studies can provide further knowledge to uncover the genetic architecture underlying heat stress in crossbred cattle.

Key words: crossbred cattle, gene network, heat stress, post-GWAS analyses

\section{INTRODUCTION}

Heat stress is an important factor in the global dairy industry, because it is responsible for large losses in milk production, growth, and reproductive performance, and negatively affects animal health and welfare (Nardone et al., 2010). Climate change may induce increases in average temperature and decreases in rainfall, leading to worsened environmental conditions for livestock production in tropical areas. Harsh environmental conditions are common in Brazil, where two-thirds of the territory is located in tropical regions, with prevalent high temperatures due to solar radiation and grazing systems dependent on the rainy season (Cruz et al., 2011).

Briefly, when animals cannot dissipate sufficient body heat to prevent an increase in their body temperature, heat stress occurs (West, 2003). Modern high-producing dairy cows are more susceptible to the deleterious effects of heat stress (Renaudeau et al., 2012) due to their very high metabolic rate associated with milk production. Bos indicus animals have a greater ability to regulate their body temperature, because they 
have undergone natural selection for thousands of years under high temperatures in India. Part of this ability is the result of lower metabolic rates and higher capacity for heat loss through thermoregulatory mechanisms, which helps in heat stress prevention (Hansen, 2004). In tropical areas, an alternative to overcome heat stress in dairy production systems is the use of crossing or synthetic breeds containing some portion of Bos indicus genetics, such as the Girolando breed, which is derived from crossing Gir and Holstein animals.

Respiration rate (RR) acts as a powerful thermoregulatory mechanism that helps maintain body temperature through evaporative cooling. This physiological parameter is important in the prediction of heat stress in dairy cattle (McDowell et al., 1975). Rectal temperature (RT) is an indicator of thermal equilibrium; an increase in this parameter expresses failure or exhaustion of thermoregulatory mechanisms, resulting in heat stress (de Andrade Ferrazza et al., 2017).

Molecular markers can help in understanding heat stress adaptive parameters of dairy cattle that are relevant to production systems in tropical regions. This approach allows the identification of genomic regions and genes associated with heat stress response, becoming an additional attribute in the process of genetic selection of heat-tolerant animals (Dikmen et al., 2015). Dikmen et al. (2013) found QTL for RT close to genes involved in cell protection against heat stress in Holstein and concluded that some SNP may be useful in genetic selection and identification of genes controlling heat tolerance. In a subsequent study, Dikmen et al. (2015) identified specific genetic markers responsible for genetic variation of thermoregulation, showing the importance of genome-wide association studies (GWAS) in finding markers and genes involved in physiological response to heat stress. However, studies about genes underlying RT, via gene-transcription factor (TF) networks and gene ontology (GO) enrichment analyses, in Bos indicus $\times$ Bos taurus animals have not been reported yet.

Recently, Vandenplas et al. (2016) developed an approach that enables the assignment of breed of origin of alleles (BOA) in crossbred animals. Results from this approach can be used to estimate SNP effects depending on the BOA and to improve genomic prediction or GWAS in crossbred animals. According to Sevillano et al. (2018), estimated effects and explained variance of SNP strongly associated with crossbred performance are different depending upon which parental breed donated them. Therefore, including breed-specific SNP effect in the genomic evaluation model allowed, in some cases, a better prediction for crossbreed performance (Sevillano et al., 2017). Otto et al. (2018) used the BOA approach to evaluate the origin of marker alleles of the candidate genes identified for tick resistance among the same population used in the current study. Those authors observed that most animals classified as resistant for tick infestation showed 2 alleles from the Gir breed, whereas susceptible animals presented 2 alleles from the Holstein breed.

In this study, we performed a GWAS in a Gir $\times$ Holstein $\mathrm{F}_{2}$ experimental population to identify SNP associated with heat stress response and used gene networks to identify the most likely candidate genes. The origins of alleles of selected genes were assigned to help understand the gene mechanisms involved in heat stress response.

\section{MATERIALS AND METHODS}

\section{Data}

The data were obtained from previous Embrapa research, in which an experimental $F_{2}$ population was produced by crossing 4 Holstein bulls with 27 Gir cows to generate $150 \mathrm{~F}_{1}(1 / 2$ Gir: $1 / 2$ Holstein) animals. From this population, $65 \mathrm{~F}_{1}$ females were mated to $4 \mathrm{~F}_{1}$ males to generate $376 \mathrm{~F}_{2}$ animals; the pedigree file contains a total of 476 animals. All $\mathrm{F}_{2}$ animals were raised together in the Embrapa Dairy Cattle experimental station, located in the southeast of Brazil (Machado et al., 2010).

A total of 341 Gir $\times$ Holstein $\mathrm{F}_{2}$ animals were subjected to a heat chamber at $42^{\circ} \mathrm{C}$ and $60 \%$ relative humidity (RH), after an adaptation period of $12 \mathrm{~h}$ at $22^{\circ} \mathrm{C}$ and $50 \% \mathrm{RH}$. Each evaluation included 6 animals, and during the whole period that the animals were housed in the heat chamber, water and food were not offered, aiming to reduce their effects on the animals' responses. Parental Gir, Holstein, and $\mathrm{F}_{1}$ animals were not subjected to heat stress.

The RT and RR of the $\mathrm{F}_{2}$ animals were evaluated in 2 replicates. The first evaluation was performed after the adaptation period, and the second evaluation $6 \mathrm{~h}$ after the heat chamber reached $42^{\circ} \mathrm{C}$. To measure RT, a digital clinical thermometer was inserted approximately 7.5 $\mathrm{cm}$ into each animal's rectum. For RR measurement, flank movements were counted for $30 \mathrm{~s}$. The difference between rectal temperature measurements was calculated, to estimate the variation of rectal temperature $(\boldsymbol{\Delta R T})$ in each animal as follows:

$$
\Delta \mathrm{RT}=R T A-R T B,
$$

where $R T A$ is the rectal temperature after heat stress and $R T B$ is the rectal temperature before heat stress (after the adaptation period). The variation of respiration rate $(\boldsymbol{\Delta R R})$ was defined similarly to $\Delta R T$. Each 
Table 1. Descriptive statistics of phenotype and covariates included in the model to evaluate the variation of rectal temperature $(\Delta \mathrm{RT})$ in an experimental Gir $\times$ Holstein $\mathrm{F}_{2}$ population evaluated for heat stress response

\begin{tabular}{|c|c|c|c|c|c|c|c|}
\hline Variable & Season $^{1}$ & \multicolumn{6}{|c|}{ Parameters } \\
\hline$\Delta \mathrm{RT}$ & 2 & 339 & 2.01 & 0.57 & 28.22 & 0.55 & 3.40 \\
\hline \multirow[t]{2}{*}{ Coat length } & 1 & 320 & 1.04 & 0.22 & 21.49 & 0.51 & 1.89 \\
\hline & 2 & 334 & 1.81 & 0.38 & 21.07 & 0.79 & 3.28 \\
\hline Coat thickness & 1 & 322 & 3.63 & 0.73 & 20.07 & 1.48 & 6.00 \\
\hline Hair density & 2 & 332 & 178.35 & 56.64 & 31.76 & 67.67 & 375.00 \\
\hline \multirow{2}{*}{$\Delta \mathrm{RR}^{2}$} & 1 & 316 & 104.88 & 19.93 & 19.01 & 58.00 & 154.00 \\
\hline & 2 & 343 & 88.34 & 28.48 & 32.23 & 12.00 & 160.00 \\
\hline $\mathrm{BC}^{3}$ & - & 369 & 0.48 & 0.05 & 10.26 & 0.31 & 0.66 \\
\hline
\end{tabular}

${ }^{1}$ Season: 1 = rainy; $2=$ dry.

${ }^{2}$ Variation of respiration rate.

${ }^{3}$ Breed composition.

animal was subjected twice to the heat chamber to perform measurement of $\Delta \mathrm{RT}$ and $\Delta \mathrm{RR}$.

Animals were evaluated in contemporary groups aged from 10 and 14 mo. Additional traits that might affect heat stress evaluations were assessed during this period: coat color, coat thickness and length, and density and type of hair (Machado et al., 2010). Ancestry was estimated using Admixture software (Alexander et al., 2009) with a reduced panel $(7,425$ SNP), pruned by linkage disequilibrium (LD) between subsequent markers.

All animals of the experimental population were genotyped with the Illumina BovineSNP50 v1 BeadChip (Illumina, San Diego, CA), including parental Gir, Holstein, $\mathrm{F}_{1}$, and $\mathrm{F}_{2}$ populations. Genotype quality control was implemented using the SNPStats package in R software (Solé et al., 2006). Samples with a call rate $<0.90$ and heterozygosity of 3.0 standard deviations above or below the observed mean were removed. For quality control of mapped SNP, only autosomal SNP with call rate $>0.90$ and minor allele frequency (MAF) $>0.03$ were considered. After quality control, the genotype file contained 40,283 SNP markers.

\section{Genome-Wide Association Analyses}

A single-SNP GWAS was performed with ASReml software (Gilmour et al., 2009), applying the following model:

$$
\begin{aligned}
y_{i j k l m n o p} & =\mu+C G_{i}+C C_{j}+H T_{k}+S N P_{l}+S_{m} \\
& +\beta_{1}\left(C L_{i j k l m n o p}-\overline{C L}\right)+\beta_{2}\left(C T_{i j k l m n o p}-\overline{C T}\right) \\
& +\beta_{3}\left(H D_{i j k l m n o p}-\overline{H D}\right)+\beta_{4}\left(V R R_{i j k l m n o p}-\overline{V R R}\right) \\
& +\beta_{5}\left(B C_{i j k l m n o p}-\overline{B C}\right)+a_{n}+p e_{o}+e_{i j k l m n o p},
\end{aligned}
$$

where $y_{i j k l m n o p}$ is the variation of rectal temperature $(\Delta \mathrm{RT}) ; \mu$ is the general mean; $C G_{i}$ is the effect accounting for contemporary groups; $C C_{j}$ is the effect accounting for coat color ( $j$ ranges from 1 to 4 ); $H T_{k}$ is the effect accounting for hair type ( $k$ ranges from 1 to 4 ); $S N P_{l}$ is the fixed effect of SNP genotype, where $l$ was coded as 0,1 , or 2 copies of one of the alleles; $S_{m}$ is the effect accounting for season (dry or rainy season); $C L_{i j k l m n o p}$ is a covariate for the effect of coat length; $C T_{i j k l m n o p}$ is a covariate for the effect of coat thickness; $H D_{i j k l m n o p}$ is a covariate for the effect of hair density; $V R R_{i j k l m n o p}$ is a covariate for the effect of $\Delta R R$, calculated by the difference between both measurements; $B C_{i j k l m n o p}$ is a covariate for the estimated indicine percent of the animal; $\beta_{1}, \beta_{2}, \beta_{3}, \beta_{4}$, and $\beta_{5}$ are the regression coefficients $a_{n}$ is a random additive genetic effect of animal $n$, assuming $a \sim N\left(0, \mathbf{A} \sigma_{a}^{2}\right)$, with additive pedigree relationship matrix $\mathbf{A}$ and the additive genetic variance $\sigma_{a}^{2} ; p e_{o}$ is the random permanent environmental effects, assuming $p e \sim N\left(0, \mathbf{I} \sigma_{p e}^{2}\right)$, with identity matrix $\mathbf{I}$ and permanent variance $\sigma_{p e}^{2}$; and $e_{i j k l m n o p}$ is the random residual effect, assuming e $\sim N\left(0, \mathbf{I} \sigma_{e}^{2}\right)$, where $\sigma_{e}^{2}$ is the residual variance. The variance components were estimated based on same model without the SNP effect.

Although the additional evaluated traits show correlation with RT control, in this work we selected $\Delta \mathrm{RT}$ as the main trait. For this reason, we included these additional traits only as covariates in the model to look for significant SNP that could be linked only to heat stress response, disregarding the effects of these additional traits on $\Delta R T$. The descriptive statistics of phenotype and covariates are shown in Table 1.

After the association analysis, the genome-wide false discovery rate (FDR) was applied to avoid false 
positives due to multiple testing. The $\mathrm{R}$ package qvalue (Dabney et al., 2014) was used to provide the $P$-values corrected for FDR ( $q$-values) for the SNP association tests. Associations with a $q$-value $\leq 0.05$ were considered significant.

A single-SNP GWAS for the $\Delta \mathrm{RR}$ trait was performed with the same model used to evaluate the $\Delta \mathrm{RT}$ trait, in which the $\Delta \mathrm{RT}$ trait was included as covariate. Nevertheless, no significant SNP was found to be associated with $\Delta R R$.

\section{QTL Regions}

We defined QTL regions based on the location of the significant SNP and the average LD (measured as the squared correlation coefficient, $\mathrm{r}^{2}$ ) in the evaluated population. Haploview software (Barrett et al., 2005) was used to calculate the pairwise LD between markers. Because the significant SNP identified in the GWAS analysis were located on chromosome 17 , we used the LD of this chromosome to fix the QTL size. In addition, the LD between significant SNP identified in GWAS (Supplemental Figures S1 and S2; https://doi.org/10 .3168/jds.2018-15305) were also used to define QTL regions. An average $\mathrm{r}^{2} \geq 0.15$ was found for SNP within a distance of $500 \mathrm{~kb}$. Thus, all significant SNP located within a region of $500 \mathrm{~kb}$ were considered as belonging to the same QTL region.

\section{Gene Search and Generation of Gene Networks}

Putative candidate genes within QTL regions were identified based on the UMD 3.1 assembly of the bovine genome (Zimin et al., 2009), using the National Center for Biotechnology Information (http://www.ncbi.nlm .nih.gov).

The gene set was used for GO enrichment analysis via the ClueGO application in Cytoscape (Bindea et al., 2009) to generate the GO. This analysis was performed based on a unilateral hypergeometric test with Bonferroni correction and aims to analyze the gene set on the search for a functional GO term or pathway that might show correlation with selected genes.

The same gene set was used to perform the analysis of regulatory sequences. For that, promoter sequences (FASTA format) were obtained by considering 3,000 bp upstream and $300 \mathrm{bp}$ downstream from genes' transcription start site in the bovine genome (Soares et al., 2017). These data were screened for the identification of enriched TF using the TFM-explorer software (http: //bioinfo.lifl.fr/TFM/TFME/), which uses weighting matrices from the JASPAR database (http://jaspar .binf.ku.dk/; Sandelin et al., 2004) to detect potential transcription factor binding sites (TFBS) of a set of gene sequences and search for over-represented TFBS. In addition, this software extracts significant groupsTFBS regions of the selected gene sequences associated with a factor - by calculating a score function threshold that was chosen to generate a $P$-value $\leq 10^{-3}$ for each position in each sequence, as described in Touzet and Varré (2007).

The TF list was then analyzed in Cytoscape software (Shannon et al., 2003), using the Biological Networks Gene Ontology tool (BiNGO; Maere et al., 2005) to determine significantly overrepresented functional GO terms. Based on the over-represented biological processes in the BiNGO tool and evidence from literature data related to the investigated traits, we were able to identify the TF most related to heat stress, allowing the generation of gene-TF interaction networks.

Gene-TF network analysis was performed in $\mathrm{Cy}$ toscape software (Shannon et al., 2003) based on the number of TFBS (connections with the selected TF) in each gene to determine the associations with $\Delta \mathrm{RT}$, which aided in the identification of the most likely candidate genes.

\section{Assignment of Breed of Origin of Alleles}

To assign the breed origin of marker alleles in the $\mathrm{F}_{2}$ population, the BOA approach (Vandenplas et al., 2016) was used with the parameter settings recommended by Sevillano et al. (2016). The BOA approach consists of 3 steps. (1) The purebred and crossbred animals' genotypes were phased with AlphaPhase 1.1 software (Hickey et al., 2011). Haplotype phasing was performed using pedigree and 9 combinations of core and tail lengths (350:50, 250:100, 300:100, 350:100, 150:200, 200:200, 250:200, 300:200, and 350:200), in which each combination was run in both "Offset" and "NotOffset" modes, allowing each allele to be considered 18 times through different haplotypes of variable length. "Offset" analysis shifts the beginning of each core to halfway along the first core, creating $50 \%$ overlaps between cores (Vandenplas et al., 2016). (2) The unique haplotypes for each pure breed were determined. In this step, it is necessary to be able to observe $80 \%$ of a haplotype's copies in a specific breed, to assign its breed of origin. (3) Breed origin was assigned to each allele observed in $\mathrm{F}_{2}$ animals based on the determined unique haplotypes.

After performing the BOA approach, $10 \%$ of $\mathrm{F}_{2}$ animals with the lowest breeding values for $\Delta \mathrm{RT}$ were designated as low- $\Delta \mathrm{RT}$, and the $10 \%$ with the highest breeding values for $\Delta \mathrm{RT}$ were designated as high- $\Delta \mathrm{RT}$. Considering the LD between SNP and genes, the physical positions of candidate genes were annotated and used as coordinates for selection of adjacent SNP, which 
were classified as HH (both alleles originated from the Holstein breed), GG (both alleles originated from the Gir breed), or HG/GH (one allele originated from the Holstein and one from the Gir breed), based on the results of the BOA approach. Finally, the alleles of each selected and classified SNP were quantified to evaluate the gametic segregation and check for prevalence of alleles from a certain breed when animals are classified as low $\Delta \mathrm{RT}$ or high $\Delta \mathrm{RT}$. For that, a chi-squared test was used to evaluate the expected gametic segregation of $25 \% \mathrm{HH}, 50 \% \mathrm{HG} / \mathrm{GH}$, and $25 \% \mathrm{GG}$ in both groups. Those SNP with a difference in prevalence of alleles from a certain breed, which did not show the expected gametic segregation, were considered significant $(P \leq$ $0.05)$.

\section{RESULTS AND DISCUSSION}

\section{Genetic Parameters}

We found heritability estimates of $0.13 \pm 0.08$ and repeatability estimates of $0.29 \pm 0.06$ for the $\Delta \mathrm{RT}$ trait. During the heat stress evaluation period, the RT was evaluated at $42^{\circ} \mathrm{C}$ and $60 \% \mathrm{RH}$, in which the temperature-humidity index (THI) was 97 . Dikmen et al. (2012) estimated heritability of $0.17 \pm 0.13$ for RT, recorded between 1500 and $1700 \mathrm{~h}$ at different THI, in Holstein cattle during summer in north Florida. In beef cattle, heritability estimates of 0.22 for RT, recorded only during summer months when the ambient temperature was $>30^{\circ} \mathrm{C}$, were found in Brahman animals, and estimates of 0.14 were found in crossbred animals showing genetic backgrounds of different tropical breeds (Porto-Neto et al., 2014).
Most studies use THI to estimate the presence or absence of the heat stress phenotype in a given environment (Biffani et al., 2016; Hagiya et al., 2017). However, evaluation of the response of each animal individually during the heat stress is relevant, as animals respond in different ways to environmental stimuli, which is accentuated in the $\mathrm{F}_{2}$ crossbred animals used in the current study because each animal possesses a unique genetic composition.

\section{QTL Regions}

In the current study, the GWAS for $\Delta$ RT identified 6 significant SNP $(q \leq 0.05)$ in the $\mathrm{F}_{2}$ population (Figure 1; Table 2). These SNP were distributed over 3 QTL regions located on Bos taurus chromosome 17 (BTA17). These QTL regions were defined based on the average LD between markers at the BTA17 and the LD between significant SNP.

Several QTL for RT single records have also been reported on other chromosomes. In purebred cattle (Angus, Simmental, and Piedmontese), QTL were identified on BTA1, 8, 10, 11, 12, 20, 22, 23, 25, 26, and 27 (Howard et al., 2014). However, the same authors annotated genes related to heat stress on BTA10, 12, 22, 23, and 25 only. Porto-Neto et al. (2014) identified significant SNP associated with RT on BTA6 and 17 in a Brahman and tropical composite population. In a GWAS for RT single records evaluated at different THI in heat-stressed Holstein animals, Dikmen et al. (2013) identified QTL on BTA4, 5, 16, 24, and 26, using the single-step genomic BLUP approach. In a subsequent study, based on previously selected SNP related to thermotolerance, Dikmen et al. (2015) identified signifi-

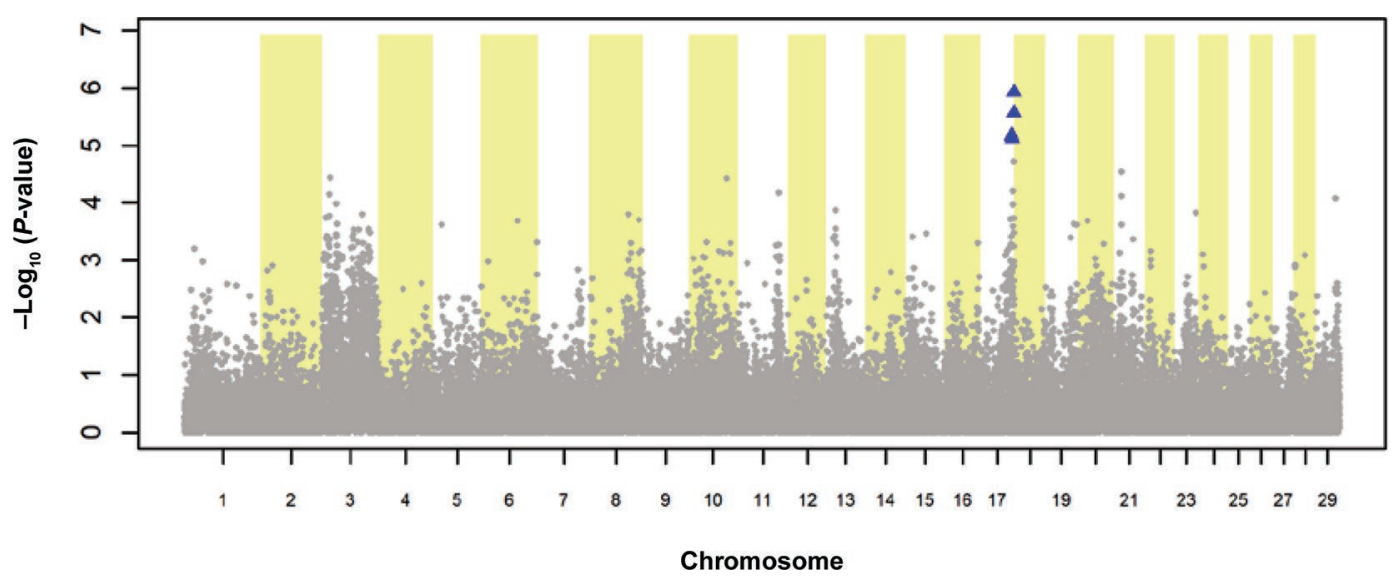

Figure 1. Manhattan plot from the association analysis of variation of rectal temperature $(\Delta \mathrm{RT})$ in the experimental Gir $\times$ Holstein $\mathrm{F}_{2}$ population. Significant SNP $(q \leq 0.05)$ are shown as blue triangles, and the gray dots denote SNP that were not significant in genome-wide association studies. 
cant SNP associated with RT single records on BTA4, 6 , and 24. Based on selected SNP located in coding regions of genes previously associated with reproduction, production or health traits, the same authors identified significant SNP associated with RT single records on BTA6, 7, 9, 10, 11, 15, 17, 18, 22 and 25. Because the regions on BTA17 were shown to be associated with RT in the current study as well as in previous studies, and also because these regions contain candidate genes that have been shown to be involved in heat stress responses (Porto-Neto et al., 2014; Dikmen et al., 2015), it is possible that these BTA17 regions may have a role in cattle heat stress.

\section{Candidate Genes}

In the current study, 54 genes encoding proteins with different functions were annotated for $\Delta \mathrm{RT}$. The gene sets were grouped according to their GO terms enrichment in a GO network to better understand their functions (Figure 2). In this network, we identified genes involved in Janus kinase/signal transducers and activators of transcription (JAK/STAT) pathway, the interleukin 6 family cytokine $(\boldsymbol{L I F})$, oncostatin M (OSM), the DGCR8 microprocessor complex subunit ( $\boldsymbol{D G C R} 8$ ), and a gene linked to the response to oxygen radical biological process, thioredoxin reductase 2 ( $T \boldsymbol{X N R D 2 ) . ~ T h e ~ O S M ~ a n d ~ L I F ~ g e n e s ~ a r e ~ c y t o k i n e s ~}$ that belong to the interleukin 6 (IL6) family, and they are closely related to the structures and functions of this cytokine family (Tanaka and Miyahima, 2003). Upon binding to cell surface receptors, IL6-type cytokines activate members of the JAK tyrosine kinase family, resulting in the activation of members of the STAT TF family, which are involved in the JAK/STAT pathway (Hong et al., 2013). During heat shock, this signaling pathway can be quickly activated by OSM and LIF cytokines, aiding in reduction of the effects stimulated by heat shock as well as in the regulation of the expression of heat shock protein (HSP) genes Hsp70 and Hsp90 (Chatterjee et al., 2007; Allegra et al., 2011; Stephanou and Latchman, 2011). In particular, STAT III shows important biological functions associated with apoptosis control, cell survival, and activation and inhibition of the immune and inflammatory responses (Loor, 2010).

The DGCR8 gene, together with nuclear RNase III enzyme Drosha, comprise the microprocessor complex, which is essential in the processing of microRNA in animals (Triboulet et al., 2009; Faller et al., 2010). According to Knuckles et al. (2017), DGCR8 and the N6adenosine-methyltransferase Mettl3 are reallocated to heat-shock genes under acute temperature stress. They work in consonance to mark $H s p 70$ mRNA, allowing subsequent RNA degradation to control the timing and magnitude of the heat-shock response. Previous studies described a significant increase in the protein expression levels of HSP in cattle subjected to heat stress (Belhadj Slimen et al., 2016; Hu et al., 2016). Clearing of HSP after heat stress is very important, to avoid accumulation of the proteins and presumably worse recovery after stress (Knuckles et al., 2017).

The TXNRD2 gene, together with the thioredoxin 2 (TRX2) and peroxiredoxin 3 (PRX3) genes, comprise the mitochondrial thioredoxin system, which provides a primary line of redox regulation through high control over reactive oxygen species (ROS) emission from mitochondria (Stanley et al., 2011; Yoshioka, 2015), which is a central source of $\mathrm{H}_{2} \mathrm{O}_{2}$. Animals exposed to heat stress show an increase in RR, and consequently $\mathrm{H}_{2} \mathrm{O}_{2}$ production exceeds its scavenging, leading to oxidative stress (Bernabucci et al., 2002; Srikandakumar and Johnson, 2004). Thioredoxin reductase 2 (TRXR2) supplies nicotinamide adenine dinucleotide phosphate (NADPH) electrons to $P R X 3$, which controls $\mathrm{H}_{2} \mathrm{O}_{2}$ levels and establishes mitochondrial redox homeostasis (Stanley et al., 2011; Aon et al., 2012). Inhibition of TRXR2 leads to impaired redox homeostasis and re-

Table 2. Significant SNP located on chromosome 17 associated with variation of rectal temperature $(\Delta \mathrm{RT})$ in an experimental Gir $\times$ Holstein $\mathrm{F}_{2}$ population evaluated for heat stress response

\begin{tabular}{lccrrr}
\hline SNP & QTL $^{1}$ & Pos $^{2}$ & \multirow{2}{*}{ Effect $^{3}$} & $-\log _{10}(P$-value $)$ & $q$-value \\
\hline BTA.41874.no.rs & 1 & $71,165,342$ & 0.15 & 5.45 & MAF $^{5}$ \\
ARS.BFGL.NGS.78729 & 1 & $71,231,159$ & 0.15 & 5.43 & 0.05 \\
ARS.BFGL.NGS.10248 & 1 & $71,260,851$ & 0.15 & 5.43 & 0.05 \\
ARS.BFGL.NGS.58770 & 2 & $74,292,319$ & 0.18 & 5.75 & 0.05 \\
ARS.BFGL.NGS.24012 & 3 & $74,948,921$ & 0.17 & 5.44 & 0.01 \\
ARS.BFGL.NGS.18349 & 3 & $74,998,349$ & 0.17 & 5.44 & 0.03 \\
\hline
\end{tabular}

${ }^{1}$ QTL region where the significant SNP is located.

${ }^{2}$ Position on the chromosome (in Mbp).

${ }^{3}$ Allele substitution effect.

${ }^{4}$ False discovery rate-based $q$-value.

${ }^{5}$ Minor allele frequency. 


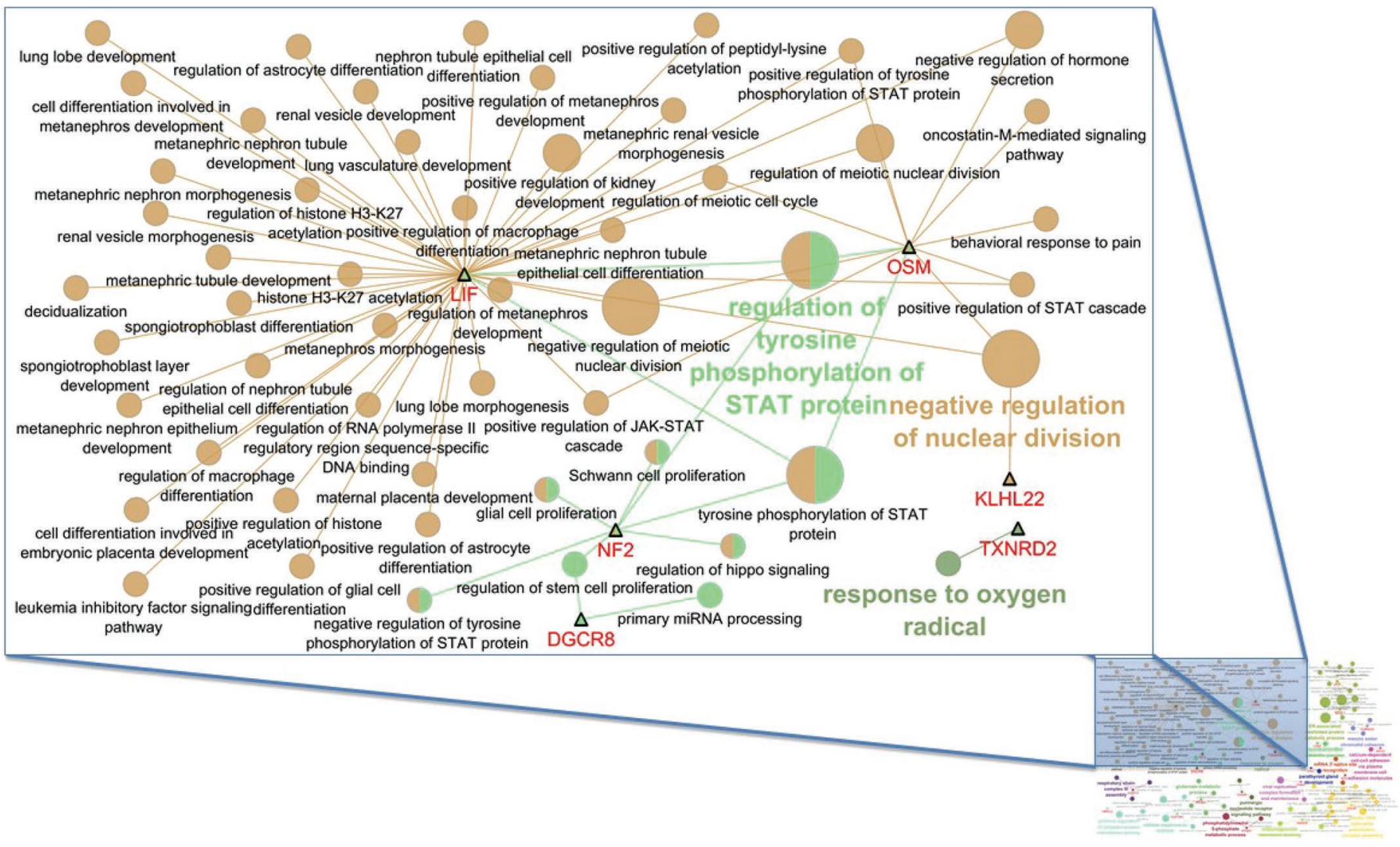

Figure 2. Functional networks showing gene interactions (triangles nodes) related to variation of rectal temperature $(\Delta \mathrm{RT})$ and the relationship across genes and their sub-networks related to positive regulation of tyrosine phosphorylation of signal transducer and activator of transcription family 3 (STAT 3) protein in the experimental Gir $\times$ Holstein $\mathrm{F}_{2}$ population. JAK $=$ Janus kinase.

sults in increased levels of $\mathrm{H}_{2} \mathrm{O}_{2}$, endangering cell functions (Prasad et al., 2014).

The same gene set was used to perform the analysis of regulatory sequences, through which, based on the biological process and literature review, we were able to identify 3 heat stress-associated TF: nuclear factor kappa B (NF- $\mathbf{B} \mathbf{B})$, aryl hydrocarbon receptor nuclear translocator (ARNT), and STAT III (Table 3). A geneTF network was generated with the 3 selected TF and genes that show potential binding sites for these $\mathrm{TF}$ (Figure 3).

The most enriched TF was NF- $\kappa \mathrm{B}$, linked to the highest number of genes. The response to heat shock has been implicated in the negative regulation of the NF- $\kappa \mathrm{B}$ signaling pathway (Yenari et al., 2005). According to Belardo et al. (2010), the effects of hyperthermic treatment are related to increase in temperature above physiological conditions and duration of exposure.

Table 3. Enriched transcription factors (TF) associated with genes identified for cattle variation of rectal temperature $(\Delta \mathrm{RT})$, based on gene ontology biological process and literature review; data obtained from an experimental Gir $\times$ Holstein $\mathrm{F}_{2}$ population evaluated for heat stress response

\begin{tabular}{|c|c|c|}
\hline $\mathrm{TF}^{1}$ & Biological process & Literature review $^{2}$ \\
\hline NF-kB & Anti-apoptosis & $\begin{array}{l}\text { Heat stress can inhibit activity of } N F-k B \text { and induce massive apoptosis (Belardo } \\
\text { et al., 2010) }\end{array}$ \\
\hline STAT III & Homeostatic process & $\begin{array}{l}\text { Cell survival regulator (Terui et al., 2004) that participates in intracellular ROS } \\
\text { homeostasis (He et al., 2010; Li et al., 2010) }\end{array}$ \\
\hline
\end{tabular}

$\overline{{ }^{1} \mathrm{ARNT}}=$ aryl hydrocarbon receptor nuclear translocator; NF- $\kappa \mathrm{B}=$ nuclear factor kappa B; STAT III $=$ signal transducer and activator of transcription family 3.

${ }^{2}$ Cited studies are just a sample of the vast available literature. 


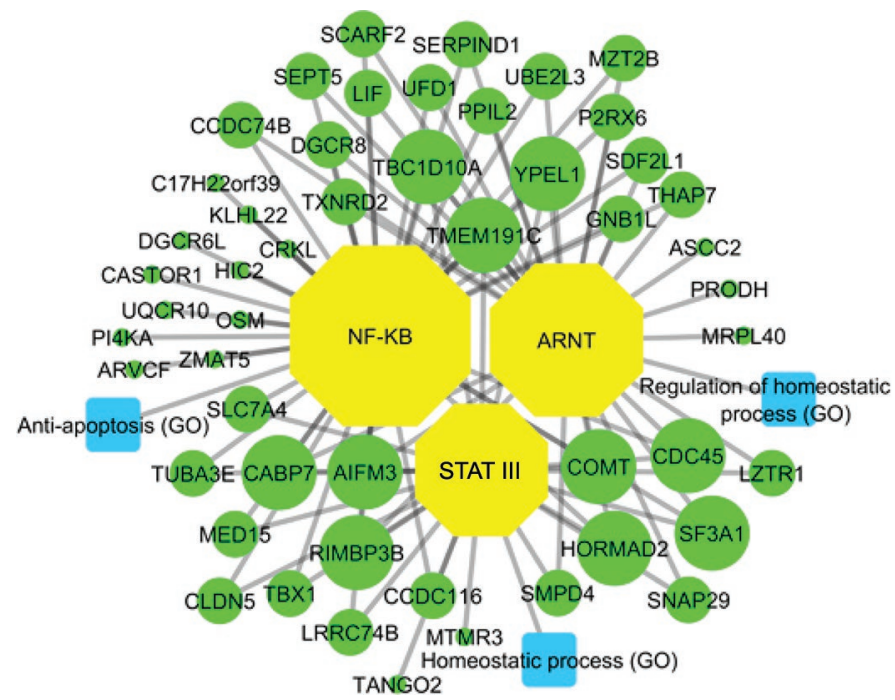

Figure 3. Gene-transcription factor (TF) network: genes located in the QTL regions associated with variation of rectal temperature ( $\Delta \mathrm{RT}$; green circle nodes) and their associated TF (yellow octagon nodes). Node size corresponds to the network analyses (Cytoscape; Shannon et al., 2003) in which larger nodes denote a higher edge density associated with the number of TF binding sites. Blue square nodes show the gene ontology biological processes related to TF. Data were obtained from an experimental Gir $\times$ Holstein $\mathrm{F}_{2}$ population evaluated for heat stress response. ARNT $=$ aryl hydrocarbon receptor nuclear

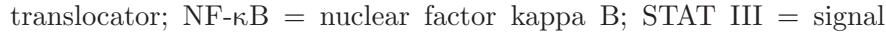
transducer and activator of transcription family 3 .

These authors observed that heat stress induced an inhibition of constitutive NF- $\kappa$ B activity in HS-Sultan cells, a B-cell lymphoma directly related to temperature increase, in addition to inhibiting the activity of $\mathrm{NF}-\kappa \mathrm{B}$ and inducing massive apoptosis in other types of aggressive B-cell neoplasms Belardo et al. (2010). In a study regarding crosstalk among cytokines and induced hyperthermia using genomic approaches, Janus et al. (2015) found a substantial overlap among the set of genes potentially regulated by heat shock protein or heat shock transcription factor 1 (HSFI) and the set of genes potentially regulated by tumor necrosis factor alpha $(\mathrm{TNF} \alpha)$ or NF- $\kappa \mathrm{B}$. This allowed the identification of predictable inhibitory effects of heat shock on the expression of classical NF- $\kappa \mathrm{B}$ target genes and new patterns of activation (or co-activation) related to responses to different types of stress and hormonal stimuli. In addition, it helped to identify repression (or co-repression) in subsets of genes associated with processes mediated by NF- $\kappa \mathrm{B}$ signaling and humoral immune responses, as well as chemokine and cytokine responses. Thus, pleiotropic effects of heat stress on the regulation of NF- $\kappa \mathrm{B}$-dependent genes should be expected.

The ARNT TF, also known as hypoxia inducible factor 1 subunit beta (HIFIB), is a subunit of transcrip- tion factor hypoxia-inducible factor 1 (hif-1; Ahn et al., 2013), a key regulator of the developmental and physiological networks required for the maintenance of $\mathrm{O}_{2}$ homeostasis. Past studies have found that hif- 1 plays an important role in preventing overproduction of mitochondrial ROS in hypoxia conditions (Semenza, 2011). After preconditioning at intermediate temperatures, HSFI promotes survival under extreme thermal stress (Kourtis et al., 2012), and according to Horowitz and Assadi (2010) its expression increased after heat acclimation-mediated cross-tolerance. Meanwhile, ARNT is involved in the negative regulation of necrosis and can be stabilized and have its expression regulated as well as its lifetime increased by heat shock proteins before and after hypoxia (Belenichev et al., 2011).

The less enriched TF in the gene-TF network (Figure 3), STAT III regulates the expression of Hsp 70 and Hsp90 genes, as previously described; it is also an important regulator of cellular survival after apoptotic stimuli (Terui et al., 2004) and directly protects cells from oxidative stress (Li et al., 2015). This TF is sensitive to intracellular oxidants and can be activated in response to ROS accumulation. Furthermore, it participates in intracellular ROS homeostasis and shows an inverse relationship with $\mathrm{NF}-\kappa \mathrm{B}$ (He et al., 2010; Li et al., 2010).

From the gene-TF network, candidate genes for $\Delta \mathrm{RT}$ were highlighted based on TFBS. The LIF, DGCR8, and TXNRD2 genes, which also share ontology in the GO enrichment analysis, are part of the most enriched gene group in this network (Figure 3).

\section{Breed of Origin of Alleles for Candidate Genes}

Based on the GO and gene-TF networks, we were able to select 4 candidate genes to assess the origin of alleles associated with $\Delta \mathrm{RT}$ in cattle. Considering the LD between SNP and genes, the physical positions of $L I F$, OSM, TXNRD2, and DGCR 8 genes were annotated and used as coordinates for selection of adjacent SNP. We selected a total of 7 SNP: 2 associated with the LIF and OSM genes, 3 associated with the TXNRD2 gene, and 2 associated with the DGCR 8 gene. The animals were grouped as low $\Delta \mathrm{RT}$ or high $\Delta \mathrm{RT}$ based on their genomic breeding values for $\Delta \mathrm{RT}$, and the alleles of the selected SNP were classified and quantified according to their breed of origin (HH, GG, or HG/GH).

Based on chi-squared test results obtained from lowand high- $\Delta \mathrm{RT} \mathrm{F}_{2}$ animals, we observed that all selected SNP for allele origin were significant $(P<0.05)$ in both evaluated groups (Table 4 ) and showed a deviation of the expected gametic segregation for each genotypic class: $1 \mathrm{HH}$ to $2 \mathrm{HG} / \mathrm{GH}$ to $1 \mathrm{GG}$. These results suggest a prevalence of alleles from one breed in the low- and 
Table 4. Percentage of individuals classified by breed of origin of each SNP allele located in the candidate genes (LIF, OSM, TXNRD2, and $D G C R 8)$ associated with variation of rectal temperature $(\triangle \mathrm{RT})$ in low- and high- $\Delta \mathrm{RT}$ animals from an experimental Gir $\times$ Holstein $\mathrm{F}_{2}$ population evaluated for heat stress response ${ }^{1}$

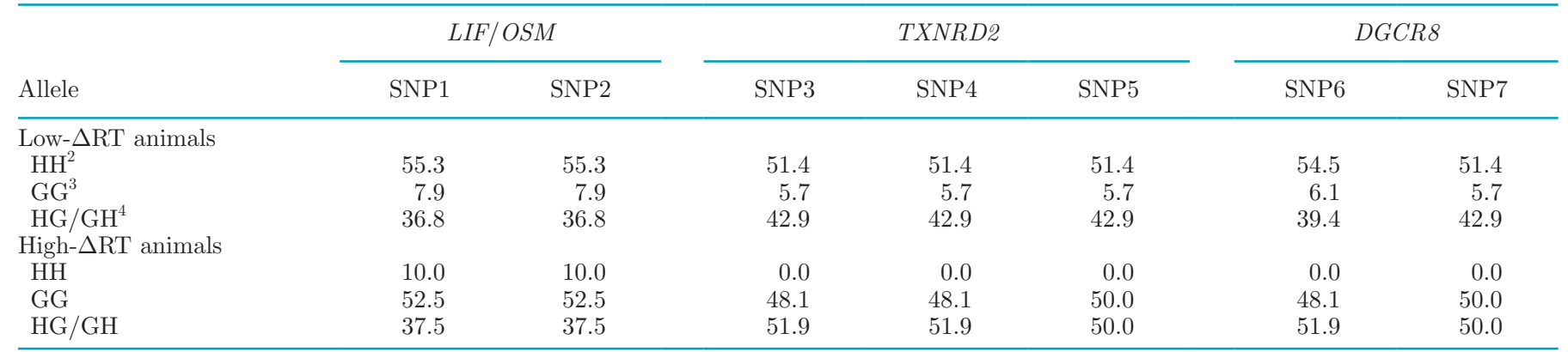

${ }^{1}$ All SNP are significant for allele origin in the chi-squared test $(P<0.05)$.

${ }^{2}$ Both alleles originated from Holstein breed.

${ }^{3}$ Both alleles originated from Gir breed.

${ }^{4}$ One allele originated from Holstein and one from Gir breed.

high- $\Delta$ RT groups. On average, $53 \%$ of low- $\Delta$ RT animals had 2 alleles from the Holstein breed, whereas $6.4 \%$ had 2 alleles from the Gir breed. On the other hand, in high- $\Delta \mathrm{RT}$ animals, the average proportion of animals for $\mathrm{HH}$ and $\mathrm{GG}$ were $2.9 \%$ and $49.9 \%$, respectively. Based on these results, we can observe that Holstein alleles are more frequent in low- $\Delta \mathrm{RT}$ animals, and Gir alleles are more abundant in high- $\Delta \mathrm{RT}$ animals.

It is known that Bos indicus animals have a greater ability to regulate their body temperature, which helps in heat stress prevention (Hansen, 2004; Cattelam and Martinez, 2013) compared with Bos taurus animals, which are affected by heat stress (Renaudeau et al., 2012). In the heat chamber, $F_{2}$ animals were subjected to high temperatures and $\mathrm{RH}$, which may have prejudiced the evaporation mechanisms, responsible for $80 \%$ of body heat loss to the environment (Shearer and Beede, 1990; West, 2003), and favored the initiation of heat stress. Given that the genes identified in our study play important functions in controlling the effects of current heat stress, and not heat stress prevention per se, it is reasonable to assume that the significant SNP alleles were derived from the Holstein breed, which requires a more efficient genetic architecture than Gir animals to defend the body from deleterious effects of heat stress.

\section{CONCLUSIONS}

In summary, the $\Delta \mathrm{RT}$ trait is a relevant phenotype for individual evaluation of heat stress response. A GWAS allowed the identification of significant SNP associated with $\Delta \mathrm{RT}$ in the experimental $\mathrm{F}_{2}$ Gir $\times$ Holstein population. Gene-TF networks and GO enrichment analyses allowed identification of candidate genes (LIF, OSM, TXNRD2, and DGCR8) that are biologically related to heat stress response. According to BOA analysis, Holstein breed alleles could be associated with a more complex response to heat stress effects, which can be explained by the fact that Holstein animals are more affected by heat stress than Gir animals, requiring an intricate genetic architecture to defend the body from the deleterious effects of heat stress. Future studies are needed to further our understanding of the genetic architecture underlying the heat stress response in crossbred cattle.

\section{ACKNOWLEDGMENTS}

We thank EMBRAPA Dairy Cattle Research Center, Fundação de Amparo à Pesquisa do Estado de Minas Gerais (FAPEMIG), Coordenação de Aperfeiçoamento de Pessoal de Nível Superior (CAPES), Conselho Nacional de Desenvolvimento Científico e Tecnológico $(\mathrm{CNPq})$, and the Ministério da Ciência Tecnologia e Inovação (MCTI)/Conselho Nacional de Desenvolvimento Científico e Tecnológico (CNPq)/Instituto Nacional de Ciência e Tecnologia-Ciência Animal (INCTCA) for their financial support, Embrapa Dairy Cattle Research Center for providing the data needed to carry out this study, and Mario P. L. Calus (Wageningen University and Research Animal Breeding and Genomics, 6700 AH Wageningen, the Netherlands) for his assistance with BOA methodology. The authors thank and acknowledge all the team effort and the visionary work done by the late Mário Luiz Martinez, former leader of this project at Embrapa Dairy Cattle Research Center.

\section{REFERENCES}

Ahn, J. E., X. Zhou, S. E. Dowd, R. S. Chapkin, and K. Zhu-Salzman. 2013. Insight into hypoxia tolerance in cowpea bruchid: Metabolic repression and heat shock protein regulation via hypoxia-induc- 
ible factor 1. PLoS One 8. https://doi.org/10.1371/journal.pone .0057267 .

Alexander, D. H., J. Novembre, and K. Lange. 2009. Fast model-based estimation of ancestry in unrelated individuals. Genome Res. 19:1655-1664. https://doi.org/10.1101/gr.094052.109.

Allegra, A., E. Sant'Antonio, G. Penna, A. Alonci, A. D'Angelo, S. Russo, A. Cannavò, D. Gerace, and C. Musolino. 2011. Novel therapeutic strategies in multiple myeloma: Role of the heat shock protein inhibitors. Eur. J. Haematol. 86:93-110. https://doi.org/ 10.1111/j.1600-0609.2010.01558.x.

Aon, M. A., B. A. Stanley, V. Sivakumaran, J. M. Kembro, B. O'Rourke, N. Paolocci, and S. Cortassa. 2012. Glutathione/thioredoxin systems modulate mitochondrial $\mathrm{H}_{2} \mathrm{O}_{2}$ emission: An experimental-computational study. J. Gen. Physiol. 139:479-491. https:/ /doi.org/10.1085/jgp.201210772.

Barrett, J. C., B. Fry, J. Maller, and M. J. Daly. 2005. Haploview: Analysis and visualization of LD and haplotype maps. Bioinformatics 21:263-265. https://doi.org/10.1093/bioinformatics/ bth457.

Belardo, G., R. Piva, and M. G. Santoro. 2010. Heat stress triggers apoptosis by impairing NF-kappaB survival signaling in malignant B cells. Leukemia 24:187-196. https://doi.org/10.1038/leu.2009 227 .

Belenichev, I. F., Y. M. Kolesnik, S. V. Pavlov, E. P. Sokolik, and N. V. Bukhtiyarova. 2011. Disturbance of HSP70 chaperone activity is a possible mechanism of mitochondrial dysfunction. Neurochem. J. 5:251-256. https://doi.org/10.1134/S1819712411040040.

Belhadj Slimen, I., T. Najar, A. Ghram, and M. Abdrrabba. 2016. Heat stress effects on livestock: Molecular, cellular and metabolic aspects, A review. J. Anim. Physiol. Anim. Nutr. (Berl.) 100:401412. https://doi.org/10.1111/jpn.12379.

Bernabucci, U., B. Ronchi, N. Lacetera, and A. Nardone. 2002. Markers of oxidative status in plasma and erythrocytes of transition dairy cows during hot season. J. Dairy Sci. 85:2173-2179. https:// doi.org/10.3168/jds.S0022-0302(02)74296-3.

Biffani, S., U. Bernabucci, A. Vitali, N. Lacetera, and A. Nardone. 2016. Short communication : Effect of heat stress on nonreturn rate of Italian Holstein cows. J. Dairy Sci.: 5837-5843. https://doi .org/10.3168/jds.2015-10491.

Bindea, G., B. Mlecnik, H. Hackl, P. Charoentong, M. Tosolini, A. Kirilovsky, W. H. Fridman, F. Pagès, Z. Trajanoski, and J. Galon. 2009. ClueGO: A Cytoscape plug-in to decipher functionally grouped gene ontology and pathway annotation networks. Bioinformatics 25:1091-1093. https://doi.org/10.1093/bioinformatics/ btp101.

Cattelam, J., and M. Martinez. 2013. Estresse térmico em bovinos. Rev. Port. Ciências Veterinárias 108:96-102.

Chatterjee, M., S. Jain, T. Stühmer, M. Andrulis, U. Ungethüm, R. J. Kuban, H. Lorentz, K. Bommert, M. Topp, D. Krämer, H. K. Müller-Hermelink, H. Einsele, A. Greiner, and R. C. Bargou. 2007. STAT3 and MAPK signaling maintain overexpression of heat shock proteins $90 \alpha$ and $\beta$ in multiple myeloma cells, which critically contribute to tumor-cell survival. Blood 109:720-728. https:/ /doi.org/10.1182/blood-2006-05-024372.

da Cruz, L. V., D. de S. R. Angrimani, B. R. Rui, and M. A. da Silva. 2011. Efeitos do estresse térmico na produção leiteira: revisão de literatura. Rev. Científica Eletrônica Med. Veterinária.

Dabney, A., Storey, J. D., Warnes, G. R., 2014. qvalue: Q-value estimation for false discovery rate control. $\mathrm{R}$ package version 1.36.0. http://github.com/jdstorey/qvalue.

Dikmen, S., J. B. Cole, D. J. Null, and P. J. Hansen. 2012. Heritability of rectal temperature and genetic correlations with production and reproduction traits in dairy cattle. J. Dairy Sci. 95:3401-3405. https://doi.org/10.3168/jds.2011-4306.

Dikmen, S., J. B. Cole, D. J. Null, and P. J. Hansen. 2013. Genomewide association mapping for identification of quantitative trait loci for rectal temperature during heat stress in Holstein cattle. PLoS One 8:e69202. https://doi.org/10.1371/journal.pone.0069202.

Dikmen, S., X.-z. Wang, M. S. Ortega, J. B. Cole, D. J. Null, and P. J. Hansen. 2015. Single nucleotide polymorphisms associated with thermoregulation in lactating dairy cows exposed to heat stress.
J. Anim. Breed. Genet. 132:409-419. https://doi.org/10.1111/jbg 12176 .

Faller, M., D. Toso, M. Matsunaga, I. Atanasov, R. Senturia, Y. Chen, Z. H. Zhou, and G. Feng. 2010. DGCR8 recognizes primary transcripts of microRNAs through highly cooperative binding and formation of higher-order structures. RNA 16:1570-1583. https://doi org/10.1261/rna.2111310.

de Andrade Ferrazza, R., H. D. Mogollón Garcia, V. H. Vallejo Aristizábal, C. de Souza Nogueira, C. J. Veríssimo, J. R. Sartori, R. Sartori, and J. C. Pinhiero Ferreira. 2017. Thermoregulatory responses of Holstein cows exposed to experimentally induced heat stress. J. Therm. Biol. 66:68-80. https://doi.org/10.1016/j .jtherbio.2017.03.014

Gilmour, A. R., B. Gogel, B. Cullis, and R. Thompson. (2009) ASReml user guide release 3.0. VSN International Ltd., Hemel Hempstead, UK.

Hagiya, K., K. Hayasaka, T. Yamazaki, T. Shirai, T. Osawa, Y. Terawaki, Y. Nagamine, Y. Masuda, and M. Suzuki. 2017. Effects of heat stress on production, somatic cell score and conception rate in Holsteins. Anim. Sci. J. 88:3-10. https://doi.org/10.1111/asj .12617 .

Hansen, P. J. 2004. Physiological and cellular adaptations of zebu cattle to thermal stress. Anim. Reprod. Sci. 82-83:349-360. https: //doi.org/10.1016/j.anireprosci.2004.04.011

He, G., G. Y. Yu, V. Temkin, H. Ogata, C. Kuntzen, T. Sakurai, W. Sieghart, M. Peck-Radosavljevic, H. L. Leffert, and M. Karin 2010. Hepatocyte IKKb/NF-kB inhibits tumor promotion and progression by preventing oxidative stress-driven STAT3 activation. Cancer Cell. 17:286-297. https://doi.org/10.1016/j.ccr.2009 .12 .048

Hickey, J. M., B. P. Kinghorn, B. Tier, J. F. Wilson, N. Dunstan, and J. H. J. van der Werf. 2011. A combined long-range phasing and long haplotype imputation method to impute phase for SNP genotypes. Genet. Sel. Evol. 43:12. https://doi.org/10.1186/1297 -9686-43-12.

Hong, D. S., U. Banerji, B. Tavana, G. C. George, J. Aaron, and R. Kurzrock. 2013. Targeting the molecular chaperone heat shock protein 90 (HSP90): Lessons learned and future directions. Cancer Treat. Rev. 39:375-387. https://doi.org/10.1016/j.ctrv.2012.10 .001 .

Horowitz, M., and H. Assadi. 2010. Heat acclimation-mediated crosstolerance in cardioprotection: Do HSP70 and HIF-1alpha play a role? Ann. N. Y. Acad. Sci. 1188:199-206. https://doi.org/10 $.1111 / \mathrm{j} .1749-6632.2009 .05101 . \mathrm{x}$

Howard, J. T. S. D. Kachman, W. M. Snelling, E. J. Pollak, D. C. Ciobanu, L. A. Kuehn, and M. L. Spangler. 2014. Beef cattle body temperature during climatic stress: A genome-wide association study. Int. J. Biometeorol. 58:1665-1672. https://doi.org/10.1007/ s00484-013-0773-5.

Hu, H., Y. Zhang, N. Zheng, J. Cheng, and J. Wang. 2016. The effect of heat stress on gene expression and synthesis of heat-shock and milk proteins in bovine mammary epithelial cells. Anim. Sci. J. 87:84-91. https://doi.org/10.1111/asj.12375.

Janus, P., T. Stokowy, R. Jaksik, K. Szoltysek, L. Handschuh, J. Podkowinski, W. Widlak, M. Kimmel, and P. Widlak. 2015. Cross talk between cytokine and hyperthermia-induced pathways: identification of different subsets of NF- $\kappa \mathrm{B}$-dependent genes regulated by TNF $\alpha$ and heat shock. Mol. Genet. Genomics 290:1979-1990. https://doi.org/10.1007/s00438-015-1055-1.

Knuckles, P., S. H. Carl, M. Musheev, C. Niehrs, A. Wenger, and M. Bühler. 2017. RNA fate determination through cotranscriptional adenosine methylation and microprocessor binding. Nat. Struct. Mol. Biol. 24:561-569. https://doi.org/10.1038/nsmb.3419.

Kourtis, N., V. Nikoletopoulou, and N. Tavernarakis. 2012. Small heatshock proteins protect from heat-stroke-associated neurodegeneration. Nature 490:213-218. https://doi.org/10.1038/nature11417.

Li, L., S.-h. Cheung, E. L. Evans, and P. E. Shaw. 2010. Modulation of gene expression and tumor cell growth by redox modification of STAT3. Cancer Res. 70:8222-8232. https://doi.org/10.1158/0008 -5472.CAN-10-0894. 
Li, L., W. Wei, Y. Zhang, G. Tu, Y. Zhang, J. Yang, and Y. Xing. 2015. SirT1 and STAT3 protect retinal pigmented epithelium cells against oxidative stress. Mol. Med. Rep. 12:2231-2238. https://doi .org/10.3892/mmr.2015.3570.

Loor, J. J. 2010. Genomics of metabolic adaptations in the peripartal cow. Animal 4:1110-1139. https://doi.org/10.1017/ S1751731110000960.

Machado, M. A., A. L. S. Azevedo, R. L. Teodoro, M. A. Pires, M. G. C. D. Peixoto, C. de Freitas, M. C. A. Prata, J. Furlong, M. V. G. B. da Silva, S. E. F. Guimarães, L. C. A. Regitano, L. L. Coutinho, G. Gasparin, and R. S. Verneque. 2010. Genome wide scan for quantitative trait loci affecting tick resistance in cattle (Bos taurus $\times$ Bos indicus). BMC Genomics 11:280. https://doi.org/10.1186/ 1471-2164-11-280.

Maere, S., K. Heymans, and M. Kuiper. 2005. BiNGO: A Cytoscape plugin to assess overrepresentation of gene ontology categories in biological networks. Bioinformatics 21:3448-3449. https://doi.org/ 10.1093/bioinformatics/bti551.

McDowell, R. E., N. W. Hooven, and J. K. Camoens. 1975. Effect of climate on performance of Holsteins in first lactation. J. Dairy Sci. 59:965-971. https://doi.org/10.3168/jds.S0022-0302(76)84305-6.

Nardone, A., B. Ronchi, N. Lacetera, M. S. Ranieri, and U. Bernabucci. 2010. Effects of climate changes on animal production and sustainability of livestock systems. Livest. Sci. 130:57-69. https:// doi.org/10.1016/j.livsci.2010.02.011.

Otto, P. I., S. E. F. Guimarães, L. L. Verardo, A. L. S. Azevedo, J. Vandenplas, A. C. C. Soares, C. A. Sevillano, R. Veroneze, M. de Fatima, A. Pires, C. de Freitas, M. C. A. Prata, J. Furlong, R. S. Verneque, M. F. Martins, J. C. C. Panetto, W. A. Carvalho, D. O. R. Gobo, M. V. G. B. da Silva, and M. A. Machado. 2018 Genome-wide association studies for tick resistance in Bos taurus $\times$ Bos indicus crossbred cattle: A deeper look into this intricate mechanism. J. Dairy Sci. 101:11020-11032. https://doi.org/10 $.3168 /$ jds.2017-14223

Porto-Neto, L. R., A. Reverter, K. C. Prayaga, E. K. F. Chan, D. J. Johnston, R. J. Hawken, G. Fordyce, J. F. Garcia, T. S. Sonstegard, S. Bolormaa, M. E. Goddard, H. M. Burrow, J. M. Henshall, S. A. Lehnert, and W. Barendse. 2014. The genetic architecture of climatic adaptation of tropical cattle. PLoS One 9:e113284. https: //doi.org/10.1371/journal.pone.0113284.

Prasad, R., L. F. Chan, C. R. Hughes, J. P. Kaski, J. C. Kowalczyk, M. O. Savage, C. J. Peters, N. Nathwani, A. J. L. Clark, H. L. Storr, and L. A. Metherell. 2014. Thioredoxin reductase 2 (TXNRD2) mutation associated with familial glucocorticoid deficiency (FGD). J. Clin. Endocrinol. Metab. 99:E1556-1563. https:/ /doi.org/10.1210/jc.2013-3844.

Renaudeau, D., A. Collin, S. Yahav, V. de Basilio, J. L. Gourdine, and R. J. Collier. 2012. Adaptation to hot climate and strategies to alleviate heat stress in livestock production. Animal 6:707-728. https://doi.org/10.1017/S1751731111002448.

Sandelin, A., W. Alkema, P. Engström, W. W. Wasserman, and B. Lenhard. 2004. JASPAR: An open-access database for eukaryotic transcription factor binding profiles. Nucleic Acids Res. 32:D91D94. https://doi.org/10.1093/nar/gkh012.

Semenza, G. L. 2011. Hypoxia-inducible factor 1: Regulator of mitochondrial metabolism and mediator of ischemic preconditioning. Biochim. Biophys. Acta. 1813:1263-1268. https://doi.org/10 .1016/j.bbamcr.2010.08.006.

Sevillano, C. A., J. Napel, S. E. F. Guimarães, F. F. Silva, and M. P. L. Calus. 2018. Effects of alleles in crossbred pigs estimated for genomic prediction depend on their breed-of-origin. 19:740. https: //doi.org/10.1186/s12864-018-5126-7.

Sevillano, C. A., J. Vandenplas, J. W. M. Bastiaansen, R. Bergsma, and M. P. L. Calus. 2017. Genomic evaluation for a three-way crossbreeding system considering breed-of-origin of alleles. Genet. Sel. Evol. 49:75. https://doi.org/10.1186/s12711-017-0350-1.

Sevillano, C. A., J. Vandenplas, J. W. M. Bastiaansen, and M. P. L. Calus. 2016. Empirical determination of breed-of-origin of alleles in three-breed cross pigs. Genet. Sel. Evol. 48:55. https://doi.org/ 10.1186/s12711-016-0234-9.

Shannon, P., A. Markiel, O. Ozier, N. S. Baliga, J. T. Wang, D. Ramage, N. Amin, B. Schwikowski, and T. Ideker. 2003. Cytoscape: A software environment for integrated models of biomolecular interaction networks. Genome Res. 13:2498-2504. https://doi.org/10 $.1101 /$ gr.1239303.

Shearer, J. K., and D. K. Beede. 1990.Thermoregulation and physiological responses of dairy cattle in hot weather. Agri-Practice. 11:5-17.

Soares, A. C. C. S. E. F. Guimarães, M. J. Kelly, M. R. S. Fortes, F F. E. Silva, L. L. Verardo, R. Mota, and S. Moore. 2017. Multipletrait genomewide mapping and gene network analysis for scrotal circumference growth curves in Brahman cattle. J. Anim. Sci. 95:3331-3345. https://doi.org/10.2527/jas.2017.1409.

Solé, X., E. Guinó, J. Valls, R. Iniesta, and V. Moreno. 2006. SNPStats: A web tool for the analysis of association studies. Bioinformatics 22:1928-1929. https://doi.org/10.1093/bioinformatics/btl268.

Srikandakumar, A., and E. H. Johnson. 2004. Effect of heat stress on milk production, rectal temperature, respiratory rate and blood chemistry in Holstein, Jersey and Australian Milking Zebu cows. Trop. Anim. Health Prod. 36:685-692. https://doi.org/10.1023/B TROP.0000042868.76914.a9.

Stanley, B. A., V. Sivakumaran, S. Shi, I. McDonald, D. Lloyd, W. H. Watson, M. A. Aon, and N. Paolocci. 2011. Thioredoxin reductase-2 is essential for keeping low levels of $\mathrm{H} 2 \mathrm{O} 2$ emission from isolated heart mitochondria. J. Biol. Chem. 286:33669-33677. https:/ /doi.org/10.1074/jbc.M111.284612.

Stephanou, A., and D. S. Latchman. 2011. Transcriptional modulation of heat-shock protein gene expression. Biochem. Res. Int. 2011 https://doi.org/10.1155/2011/238601.

Tanaka, M., and A. Miyahima. 2003. Onconstatin M, a multifunctional cytokine. Rev. Physiol. Biochem. Pharmacol. 149:39-52. https:/ /doi.org/10.1007/s10254-003-0013-1.

Terui, K., S. Enosawa, S. Haga, H. Q. Zhang, H. Kuroda, K. Kouchi, T. Matsunaga, H. Yoshida, J. F. Engelhardt, K. Irani, N. Ohnuma, and M. Ozaki. 2004. Stat3 confers resistance against hypoxia/ reoxygenation-induced oxidative injury in hepatocytes through upregulation of Mn-SOD. J. Hepatol. 41:957-965. https://doi.org/10 $.1016 /$ j.jhep.2004.08.019.

Touzet, H., and J.-S. Varré. 2007. Efficient and accurate P-value computation for Position Weight Matrices. Algorithms Mol. Biol. 2:15. https://doi.org/10.1186/1748-7188-2-15.

Triboulet, R., H. M. Chang, R. J. Lapierre, and R. I. Gregory. 2009. Post-transcriptional control of DGCR8 expression by the Microprocessor. RNA 15:1005-1011. https://doi.org/10.1261/rna .1591709 .

Vandenplas, J., M. P. L. Calus, C. A. Sevillano, J. J. Windig, and J. W. M. Bastiaansen. 2016. Assigning breed origin to alleles in crossbred animals. Genet. Sel. Evol. 48:61. https://doi.org/10.1186/ s12711-016-0240-y.

West, J. W. 2003. Effects of heat-stress on production in dairy cattle J. Dairy Sci. 86:2131-2144. https://doi.org/10.3168/jds.S0022 -0302(03)73803-X.

Yenari, M. A., J. Liu, Z. Zheng, Z. S. Vexler, J. E. Lee, and R. G. Giffard. 2005. Antiapoptotic and anti-inflammatory mechanisms of heat-shock protein protection. Ann. N. Y. Acad. Sci. 1053:7483. https://doi.org/10.1196/annals.1344.007.

Yoshioka, J. 2015. Thioredoxin reductase 2 (Txnrd2) regulates mitochondrial integrity in the progression of age-related heart failure. J. Am. Heart Assoc. 4:1-3. https://doi.org/10.1161/JAHA.115 .002278 .

Zimin, A. V., A. L. Delcher, L. Florea, D. R. Kelley, M. C. Schatz, D. Puiu, F. Hanrahan, G. Pertea, C. P. Van Tassell, T. S. Sonstegard, G. Marçais, M. Roberts, P. Subramanian, J. A. Yorke, and S. L. Salzberg. 2009. A whole-genome assembly of the domestic cow, Bos taurus. Genome Biol. 10. https://doi.org/10.1186/gb-2009-10 $-4-\mathrm{r} 42$. 